\title{
EFEITO DO TRATAMENTO TÉRMICO E ENZIMÁTICO NAS PROPRIEDADES DE FILMES DE GELATINA ${ }^{1}$
}

\author{
Rosemary Aparecida de CARVALHO ${ }^{2 *}$, Carlos Raimundo Ferreira GROSSO ${ }^{3}$
}

\begin{abstract}
RESUMO
Dentre os fatores que afetam a atividade da enzima transglutaminase, a temperatura de reação ou incubação é um fator determinante no grau de reticulação. Por outro lado, para a gelatina, tipicamente a rede estrutural polimérica é estabilizada por forças secundárias, sendo que a formação da matriz polimérica envolve um delicado balanço entre interações polímero-polímero e polímero-solvente, e este balanço é fortemente dependente do histórico térmico da solução. Desta forma, o objetivo deste trabalho foi avaliar o efeito da temperatura na reação de modificação enzimática em relação às propriedades funcionais dos filmes modificados à base de gelatina (propriedades mecânicas, de barreira ao vapor de água, solubilidade em água e parâmetros de cor dos filmes). Viscosidade aparente das soluções filmogênicas foram também avaliadas. Foram produzidos filmes denominados nativo (FN), modificado enzimaticamente (FME) e termicamente tratado (FC). De acordo com os resultados obtidos, observou-se que a temperatura de reação não afetou as propriedades mecânicas e a solubilidade dos diferentes filmes estudados. Por outro lado, filmes modificados enzimaticamente (FME) na temperatura de $50{ }^{\circ} \mathrm{C}$ apresentaram permeabilidade ao vapor de água significantemente inferior aos produzidos nas demais temperaturas e tratamentos ( $\mathrm{FN}$ e FC). O tratamento térmico também provocou redução da permeabilidade ao vapor de água.

Palavras-chave: filmes, temperatura de reação, transglutaminase.
\end{abstract}

\section{SUMMARY}

EFFECT OF THERMAL AND ENZYMATIC TREATMENT ON THE PROPERTIES OF GELATIN FILMS. The activity of transglutaminase (one crosslinking enzyme) can be affected by the temperature of reaction. Gelatin matrix gel formation depends on the balance between polymer-polymer interactions and a polymer-solvent solution. This balance also depends on the amount and type of thermal treatment to the gelatin solution. The aim of this work is to evaluate the effect of the temperature on the crosslinking reaction using transglutaminase. Mechanical properties, water vapor permeability, water solubility and color/opacity of the films were evaluated. Viscosity of the solutions was also evaluated. Native film (FN), enzymatically modified film (FME) and thermal treated film (FC) were produced. According to the results, the temperature which was used did not significantly change the mechanical properties and the solubility of the films produced using different treatments. Enzymatically modified films at $50{ }^{\circ} \mathrm{C}$ showed the lowest water vapor permeability compared to the other temperatures and treatments ( $F N$ e FC). Thermal treatment also caused a reduction in the water vapor permeability.

Keywords: films, temperature of reaction, transglutaminase.

\section{1 - INTRODUÇÃO}

A gelatina, devido às suas propriedades funcionais tem sido explorada em estudos envolvendo a formação de filmes comestíveis e/ou biodegradáveis [6, 21, 22]. Filmes à base de proteínas apresentam efetiva barreira a gases $\left(\mathrm{CO}_{2} \mathrm{e}_{2}\right)$, porém alta permeabilidade ao vapor de água [5] em função do seu caráter hidrofílico, o que limita sua aplicação na forma de embalagens.

O aumento do grau de ligações intra e intermoleculares, por meio de de reações enzimáticas, pode provocar o aumento da coesão da matriz polimérica, com conseqüente alteração de sua funcionalidade, incluindo a diminuição da solubilidade e da permeabilidade ao vapor de água. A transglutaminase catalisa reações de acil-transferência

\footnotetext{
${ }^{1}$ Recebido para publicação em 10/9/2004. Aceito para publicação em 6/7/2006 (001404)

${ }^{2}$ Universidade Estadual de São Paulo (FZEA/ZEZ),

Av. Duque de Caxias Norte, n. 225,

CEP 13635-900, Pirassununga (SP), Brasil

E-mail: rcarvalho@fzea.usp.br

${ }^{3}$ Universidade Estadual de Campinas,

Departamento de Alimentos e Nutrição,

CEP 13083-862, Campinas (SP), Brasil

* A quem a correspondência deve ser enviada
}

entre grupos $\gamma$-carboxiamídico e resíduos de glutamina da cadeia polipeptídica (acil-doadores) e uma variedade de aminas primárias (acil-receptores), incluindo os grupos E-amino de resíduos de lisina em certas proteínas [27]. Modificações funcionais decorrentes do aumento de ligações cruzadas foram estudadas em vários sistemas. SAKAMOTO, KUMAZANA \& MOTOKI [19], para géis de isolado protéico de soja, proteínas do ovo e gelatina, observaram aumento da força de ruptura em géis incubados com transglutaminase. YILDIRIM \& HETTIARACHCHY [25], para filmes protéicos à base de isolado protéico de soja e globulina $11 \mathrm{~S}$, verificaram que o tratamento com a enzima transglutaminase provocou diminuição da solubilidade dos filmes em tampões aquosos em diferentes pHs e aumento na tensão na ruptura, indicando a introdução de ligações covalentes na estrutura protéica.

Entre os fatores que afetam a atividade da enzima transglutaminase, a temperatura de reação ou incubação é um fator determinante no grau de reticulação. Por outro lado, para a gelatina, tipicamente a rede estrutural polimérica é estabilizada por forças secundárias, sendo que a formação da matriz polimérica envolve um balanço entre interações polímero-polímero e polímero-solvente, e este balanço é fortemente dependente do histórico térmico da solução [11, 23]. SAKAMOTO, KIMAZANA \& MOTOKI [19], estudando o efeito da temperatura de incubação em géis à base de gelatina 
tratados com transglutaminase, verificaram que géis com maior dureza foram obtidos na temperatura de $50{ }^{\circ} \mathrm{C}$. Por outro lado, GÓMEZ-GUILLÉN et al. [9], estudando o efeito da enzima e do tratamento térmico na força de géis à base de gelatina, verificaram que o tratamento térmico durante 15 min a $90{ }^{\circ} \mathrm{C}$, provocou uma redução na dureza dos géis tratados com transglutaminase em relação a filmes sem enzima e com enzima submetido a um tratamento térmico de 5 min a $90{ }^{\circ} \mathrm{C}$. Entretanto, estudos referentes ao efeito da temperatura de incubação da enzima transglutaminase nas propriedades funcionais de filmes comestíveis e/ou biodegradáveis não estão disponíveis na literatura. Desta forma, o objetivo deste trabalho foi avaliar o efeito da temperatura da reação de modificação enzimática nas propriedades mecânicas, de barreira, na solubilidade em água e nos parâmetros de cor de filmes à base de gelatina. A viscosidade aparente das soluções filmogênicas foi também avaliada após os tratamentos.

\section{2 - MATERIAL E MÉTODOS}

\section{1 - Materiais}

Gelatina do Tipo B (bloom $=270,0$ g; granulometria $<0,60 \mathrm{~mm}$; proteína $=88,92 \pm 0,02 \%$; cinzas $=0,78 \pm$ $0,01 \%$; umidade $=10,3 \pm 0,1 \%$ ) doada pela indústria Gelita South America (São Paulo, SP, Brasil); enzima transglutaminase ACTIVA-TGS (produzida por microorganismos, $\mathrm{Ca}^{+2} /$ independente) doada pela indústria Ajinomoto Interamericana Indústria e Comércio Ltda; glicerol (Merck, São Paulo, SP, Brasil); e nitrato de magnésio $\left(\mathrm{Mg}\left(\mathrm{NO}_{3}\right)_{2} \cdot 6 \mathrm{H}_{2} \mathrm{O}\right.$; Sinth, São Paulo, SP, Brasil).

\section{2 - Produção do filme}

Foram produzidos os seguintes filmes: modificados com a enzima transglutaminase (FME), sem modificação denomidado nativo (FN) e sem modificação submetidos aos mesmos tratamentos térmicos envolvidos na produção de filmes modificados enzimaticamente (FC). Os filmes, com $10 \mathrm{~g}$ de gelatina e 4,5 g de glicerol/100 g de solução filmogênica, foram preparados da seguinte maneira: hidratação da gelatina $\left(25^{\circ} \mathrm{C}, 60 \mathrm{~min}\right)$, solubilização em água destilada em banho com agitação mecânica nas temperaturas de 40, 50,60 e $70{ }^{\circ} \mathrm{C}$ ( $15 \mathrm{~min}$ ), incorporação do glicerol e, no caso do FME, da enzima transglutaminase. A enzima transglutaminase foi utilizada na concentração de $10 \mathrm{U} / \mathrm{g}$ de gelatina. Após a solubilização e incorporação do plastificante e do agente reticulante, a solução foi mantida sob agitação mecânica por um período de 15 min nas temperaturas acima mencionadas. No caso da produção dos filmes FME e FC, a solução filmogênica foi submetida a um tratamento térmico adicional por 15 min a $85{ }^{\circ} \mathrm{C}$ para a inativação da enzima. Após os tratamentos, as soluções filmogênicas foram dispersas em placas de acrílico (9,0 cm de diâmetro) e submetidas à secagem à temperatura ambiente $\left(25^{\circ} \mathrm{C}\right)$ por 24 a $48 \mathrm{~h}$. A espessura dos filmes (média de 15 medidas aleatórias) foi mantida constante em 0,080 $\pm 0,004 \mathrm{~mm}$ por meio da relação massa/área e foi determinada utilizando-se um micrômetro digital (Mitutoyo Corp., Tokyo, Japan). Anteriormente às análises, os filmes foram acondicionados por $72 \mathrm{~h}\left(25 \pm 2{ }^{\circ} \mathrm{C}\right)$ em dessecadores contendo solução salina saturada de $\mathrm{MgNO}_{3}$ (50 $\pm 3 \%$ Umidade Relativa, UR; $25 \pm$ $2{ }^{\circ} \mathrm{C}$ ). Todas as caracterizações dos filmes foram realizadas em salas climatizadas, 24 a $26{ }^{\circ} \mathrm{C}$ e $50-60 \%$ UR.

\section{3 - Viscosidade aparente}

Foram determinadas as viscosidades das soluções: para produção dos filmes nativos (SFN); para produção dos filmes modificados enzimaticamente (SFME); e para produção dos filmes termicamente tratados (SFC). As soluções filmogênicas foram produzidas de acordo com o procedimento descrito anteriormente. A viscosidade aparente das soluções filmogênicas foi determinada utilizando-se um viscosímetro Synchro-Letric, DVDII+ (Brookfield, Stoughton, MA, USA), a temperatura de $50{ }^{\circ} \mathrm{C}$, utilizando-se haste $\mathrm{N}^{\circ} 18$ e velocidade de rotação de $50 \mathrm{rpm}$, em triplicata.

\section{4 - Propriedades mecânicas}

A tensão na ruptura (TR) e a elongação (E) dos filmes, média de cinco repetições, foram determinadas utilizando-se um texturômetro TA.XT2 (TA Instruments, New Castle, U.S.A.) de acordo com o método ASTM D882-95 [2]. Para o teste, os filmes foram cortados em retângulos $(2,58 \times 9,0 \mathrm{~cm})$ e a distânica inicial de separação e a velocidade de realização dos testes foram fixadas em $50 \mathrm{~mm}$ e $1 \mathrm{~mm} / \mathrm{s}$, respectivamente (TA.TX2 - Modo Tensão). A força de tensão (FT) foi calculada dividindo-se a força máxima no rompimento do filme pela área da seção transversal, e a elongação foi calculada dividindose o aumento do comprimento do filme pelo comprimento inicial do filme $(\Delta \mathrm{l} / \mathrm{lo})$ e expressa em porcentagem.

\section{5 - Material solúvel em água}

A porcentagem de material total solúvel em água dos filmes foi determinada segundo o método proposto por CUQ et al. [7]. Amostras (2,0 cm de diâmetro) foram imersas em $50 \mathrm{~mL}$ de água destilada e o sistema foi mantido sob agitação mecânica suave utilizando-se um banho termostático com agitação mecânica (FANEN modelo-28C, São Paulo, SP, Brasil) por $24 \mathrm{~h}$ a $25{ }^{\circ} \mathrm{C}$. A massa inicial foi determinada em função da umidade da amostra. Após 24 h, as amostras foram retiradas da solução e submetidas à secagem em estufa com circulação forçada de $\operatorname{ar}\left(105^{\circ} \mathrm{C}, 24 \mathrm{~h}\right)$.

\section{6 - Cor e opacidade}

Os parâmetros de cor croma a $\left(\mathrm{a}^{*}\right)$, croma b ( $\left.\mathrm{b}^{*}\right)$, luminosidade $\left(\mathrm{L}^{*}\right)$ e a opacidade foram determinados utilizando-se um colorímetro COLORQUEST II (Hunterlab, Reston, VI, USA), sendo as determinações realizadas em triplicata. Os filmes foram sobrepostos a um padrão branco $\left(\mathrm{L}^{*}=84,67 ; \mathrm{a}^{*}=-0,55 \mathrm{e} \mathrm{b}^{*}=0,68\right)$ para a determinação de $L^{*}, a^{*}$ e b* [10]. 
A opacidade foi determinada utilizando-se o software do equipamento de acordo com SOBRAL [21], sendo calculada como a relação entre a opacidade do filme sobreposto ao padrão preto $\left(P_{\text {preto }}\right)$ e ao padrão branco $\left(P_{\text {branco }}\right)$, segundo a Equação 1.

Opacidade $(\%)=\frac{P_{\text {preto }}}{P_{\text {branco }}} \times 100$

\section{7 - Permeabilidade ao vapor de água}

A permeabilidade ao vapor de água (PVA) dos filmes foi determinada gravimetricamente, em triplicata, de acordo com o método ASTM E96-95 [3], utilizando-se célula padronizada de alumínio ( $76 \mathrm{~mm}$ de diâmetro interno e $18 \mathrm{~mm}$ de altura). O interior da célula foi preenchido com silica gel e o filme fixado com parafina. A célula foi acondicionada em dessecadores contendo solução salina saturada de $\mathrm{MgNO}_{3}$ (50 $\pm 3 \%$ UR). Os dessecadores foram mantidos em incubadora com controle eletrônico de temperatura (BOD; Tecnal, TE-390) na temperatura de $25 \pm 2{ }^{\circ} \mathrm{C}$. O gradiente de UR foi de 50:0\% (UR externa: UR interna). As células foram pesadas $( \pm 0,0001 \mathrm{~g})$ diariamente até peso constante. A permeabilidade ao vapor de água foi calculada utilizandose a Equação 2:

$P V A=\frac{W X}{t A P_{0}\left(U R_{1}-U R_{2}\right)}$

onde $w / t$ é o ganho de massa (fluxo, g/h), $x$ é a espessura do filme (mm), A é a área do filme exposta à permeação $\left(\mathrm{m}^{2}\right), P_{0}$ é a pressão de vapor da água pura $\left(\mathrm{T}=25^{\circ} \mathrm{C}, P_{0}=3,159 \mathrm{KPa}\right)$ e $\left(U R_{1}-U R_{2}\right)$ é o gradiente de umidade relativa utilizado no teste.

\section{3 - RESULTADOS E DISCUSSÃO}

\section{1 - Viscosidade aparente}

O efeito da temperatura na viscosidade aparente $\left(\eta_{\text {aparente }}\right)$ das soluções filmogênicas, modificada enzimaticamente (SFME), nativa (SFN) e termicamente tratada (SFC) pode ser observado na Figura 1. Os resultados indicaram que o aumento da temperatura de incubação provocou um aumento significativo $(\mathrm{p}<0,05)$ da viscosidade da solução filmogênica modificada enzimaticamente (SFME), na faixa de 40 a $60{ }^{\circ} \mathrm{C}$, em relação à solução filmogênica sem modificação (SFN) e termicamente tratada (SFC).

Foi também observado que a SFME produzida na temperatura $50{ }^{\circ} \mathrm{C}$ apresentou viscosidade superior às soluções produzidas nas demais temperaturas estudadas. Este aumento pode estar relacionado à maior exposição de grupos reativos favoráveis à formação de ligações cruzadas que, por sua vez, provocaram o aumento da reticulação e um acentuado aumento da viscosidade aparente. O aumento da viscosidade em soluções tratadas com a enzima transglutaminase, devido à formação de ligações cruzadas, foi anteriormente observado para isolado protéico de soro de leite [8, 13], para caseinato de sódio [13] e para $\alpha_{\mathrm{S1}}$-caseína [15].

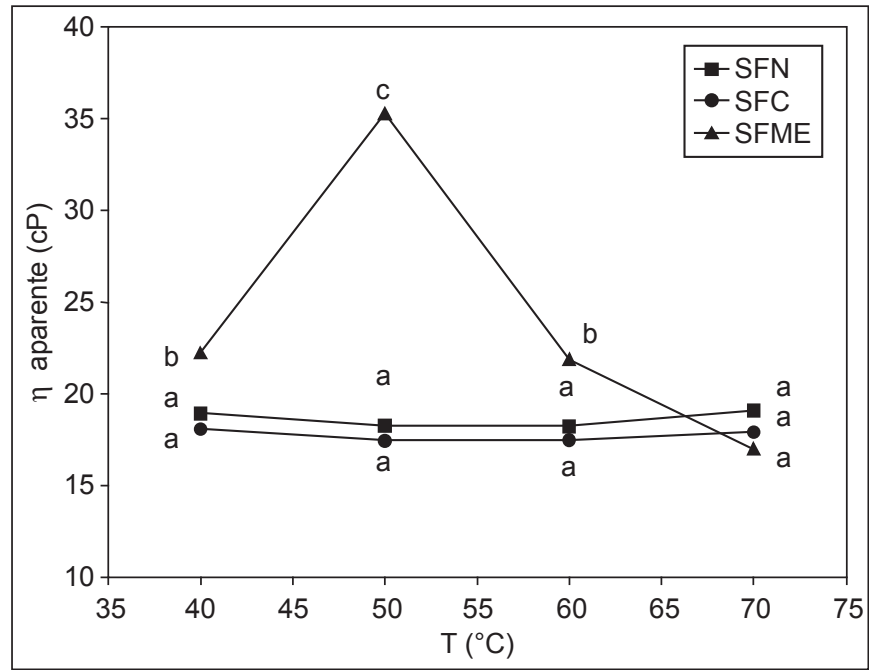

FIGURA 1 - Efeito da temperatura na viscosidade aparente $\left(\eta_{\text {aparente }}\right)$ das soluções: para produção do filme nativo (SFN), para produção do filme modificado enzimaticamente (SFME) e para a produção do filme termicamente tratado (SFC). Nota: $a, b=$ letras diferentes representam diferença significativa $(\mathrm{p}<0,05)$ entre as médias obtidas por meio do "teste TUKEY".

Os resultados obtidos indicaram ainda que o tratamento térmico $\left(85^{\circ} \mathrm{C}, 10 \mathrm{~min}\right)$ provocou uma leve diminuição da viscosidade aparente da SFC (solução filmogênica de gelatina não modificada enzimaticamente), na faixa de temperatura estudada, em relação à SFN. A exposição da solução filmogênica a altas temperaturas pode levar a modificações das interações proteína-proteína, alterações do grau de agregação das moléculas e conseqüentemente à variação da viscosidade aparente. Este fato pode estar relacionado ainda com a hidrólise de peptídeos [23], provocando uma diminuição da massa molecular e conseqüentemente da viscosidade aparente o que, entretanto, não foi observado para a solução filmogênica tratada enzimaticamente.

\section{2 - Material solúvel em água}

Os resultados apresentados na Figura 2 indicaram que o aumento da temperatura de reação $\left(40\right.$ a $\left.70{ }^{\circ} \mathrm{C}\right)$ não provocou alterações significativas $(\mathrm{p}<0.05)$ na porcentagem de material solúvel em água dos filmes tratados com transglutaminase (FME) entre as diferentes temperaturas estudadas. Entretanto, é claramente observável (Figura 2) que o tratamento com a enzima transglutaminase provocou redução da solubilidade em água dos filmes modificados (FME) em relação aos filmes nativo (FN) e termicamente tratado (FC) em todas as temperaturas estudadas, o que sugere que ocorreu formação de ligações cruzadas intermoleculares e diminuição de peptídeos de pequeno peso molecular e monômeros, o que favoreceu o decréscimo da solubilidade em relação aos filmes sem tratamento enzimático. Resultados semelhantes foram encontrados por YILDIRIM \& HETTIARACHCHY [26] para filmes à base de concentrado protéico de soro de leite. Por outro lado, observou-se (Figura 2) que os filmes termicamente tratados (FC) apresentaram um leve aumento da 
porcentagem de matéria solúvel em relação ao filme nativo $(\mathrm{FN})$. O aumento do tratamento térmico pode ter provocado maior exposição de monômeros, peptídeos de pequena massa molecular e materiais não protéicos, levando a um aumento da solubilidade desses filmes [24]. Contrariamente aos resultados aqui observados, PÉRES-GAGO, NADAUD \& KROCHTA [17], para filme à base de isolado protéico do soro de leite, observaram diminuição, em torno de $75 \%$, da solubilidade dos filmes tratados termicamente em relação ao filme nativo sem tratamento. Esses autores sugeriram que o tratamento térmico provocou a formação de uma matriz filmogênica com maior grau de coesividade e favoreceu a formação de ligações dissulfídicas covalentes intermoleculares que levaram à formação de um filme menos solúvel em água.

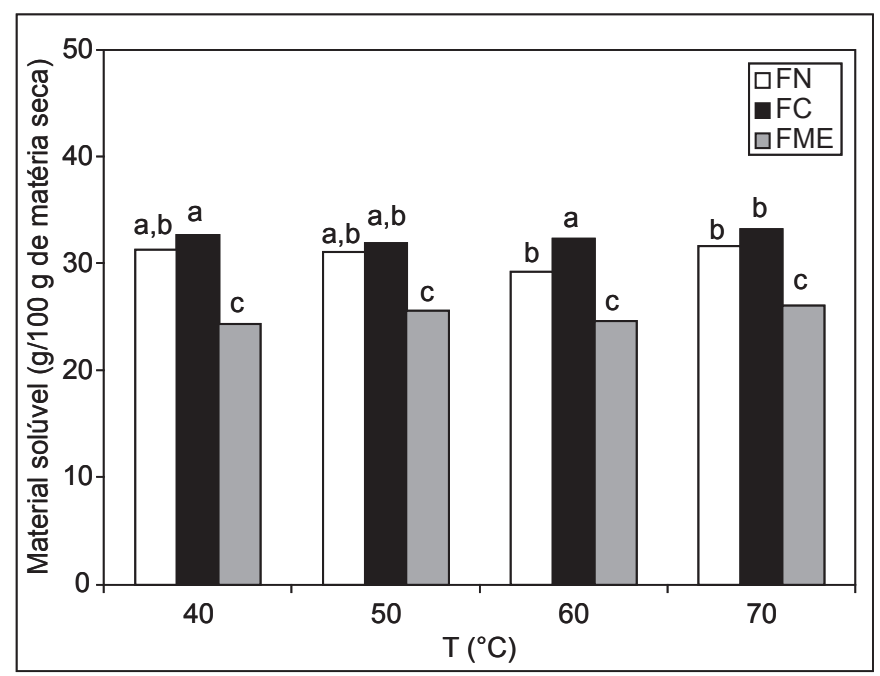

FIGURA 2 - Matéria solúvel em água $\left(25^{\circ} \mathrm{C}\right)$ de filmes modificados enzimaticamente (FME), termicamente tratados (FC) e nativo (FN) em função da variação da temperatura. Nota: $a, b=$ letras diferentes representam diferença significativa $(p<0,05)$ entre as médias, obtidas por meio do "teste TUKEY".

\section{3 - Propriedades mecânicas}

Na Tabela 1, pode-se observar o efeito da temperatura de reação nas propriedades mecânicas dos filmes de gelatina modificados enzimaticamente, nativo e termicamente tratados. Para os três tratamentos estudados, valores de TR ligeiramente superiores foram observados para a temperatura de $50{ }^{\circ} \mathrm{C}$ em relação às outras temperaturas estudadas. Considerando os maiores valores de TR, obtidos a $50{ }^{\circ} \mathrm{C}$, não foram observadas diferenças entre os tratamentos indicando que a reação enzimática não produziu efeito sobre a tensão de ruptura dos filmes, embora SAKAMOTO, KUMAZAMA \& MOTOKI [19], estudando o efeito da temperatura de reação na dureza de géis à base de gelatina tratada com a enzima transglutaminase, verificaram que géis de maior dureza foram obtidos quando a temperatura utilizada foi de $50{ }^{\circ} \mathrm{C}$.
YILDIRIM \& HETTIARACHCHY [26], para filmes à base de isolado protéico de soro de leite (WPI), globulina (11S) e misturas de WPI: 11S, observaram um aumento da tensão na ruptura dos filmes modificados enzimaticamente, em relação ao filme sem tratamento, de 5,64 para $12,53 \mathrm{MPa} ; 7,61$ para $16,41 \mathrm{MPa}$, e de 6,26 para 17,86 MPa para as diferentes relações WPI: 11S. Os autores justificaram os acréscimos como consequência do aumento do nível de reticulação da matriz polimérica e da formação de redes protéicas mais coesas. BABIN \& DICKINSON [4], estudando o efeito da enzima transglutaminase na gelificação de gelatinas, observaram que a formação de ligações intra e intermoleculares provocadas pela enzima dificultava a formação física das zonas de junção durante o resfriamento, o que determinava as características reológicas do gel formado, provocando uma diminuição de seu módulo elástico. Assim, a dificuldade de renaturação e, conseqüente, diminuição das zonas de junção formadas (características do colágeno), em função da introdução de ligações $\varepsilon$-( $\gamma$-glutamil)lisina entre as cadeias peptídicas, parecem não favorecer as propriedades mecânicas dos filmes à base de gelatina modificada com transglutaminase.

Aumento de temperatura $\left(70^{\circ} \mathrm{C}\right)$ produziu os menores valores de TR obtidos entre todos os tratamentos estudados. No caso da gelatina, em função de sua estrutura fibrilar, a formação de géis é resultado da renaturação parcial de moléculas desordenadas em estruturas características do colágeno [1,28]. As estruturas renaturadas da tripla hélice funcionam como zonas de junção na formação da rede tridimensional. O grau de renaturação depende, dentre outros fatores, da concentração e da temperatura utilizados [1, 28]. Uma possível hipótese para este fato está relacionada com a cinética de gelatinização composta por três estágios [1, 28]: nucleação $\rightarrow$ crescimento $\rightarrow$ estabilização. A etapa de crescimento está diretamente relacionada com a temperatura e, nesta etapa, em função da, variação são formadas zonas de junção largas (pequenas variações de temperatura) ou ainda pequenas zonas de junção em número elevado (grande variação de temperatura). Para temperatura de $70{ }^{\circ} \mathrm{C}$, aparentemente, em função da elevada temperatura durante todo o processo, a formação de zonas de junção menores pode ter ocorrido provocando uma diminuição da resistência à tensão. Para proteínas globulares, resultado contrário foi observado por PÉREZ-GAGO, NADAUD \& KROCHTA [17], em que filmes à base de proteínas do soro de leite, apresentaram aumento significativo da tensão na ruptura, em virtude do tratamento térmico, sugerindo um desdobramento da estrutura globular da proteína, possibilitando a formação de ligações dissulfídicas e a formação de redes protéicas mais estruturadas.

O tratamento com a enzima transglutaminase provocou redução da elongação (Tabela 1) dos filmes modificados (FME) em relação ao filme nativo (FN) e tratado termicamente FC). Aparentemente, a reticulação, reduziu a mobilidade da matriz polimérica provocando diminuição da elasticidade dos filmes tratados com transglutaminase. Resultados contrários foram observados por LI \& CHEN [12], em que um aumento da elongação foi observado em função do intercruzamento da matriz polimérica. 
TABELA 1 - Variação da tensão na ruptura (TR) e da elongação (E) em função da temperatura de reação para os filmes: modificado enzimaticamente (FME), termicamente tratado (FC) e nativo $(\mathrm{FN})$.

\begin{tabular}{cccc}
\hline $\mathbf{T}\left(^{\circ} \mathbf{C}\right)$ & $\mathbf{F M E}$ & $\mathbf{F C}$ & $\mathbf{F N}$ \\
\cline { 2 - 4 } & \multicolumn{3}{c}{$\mathbf{T R}(\mathbf{M p a})$} \\
\hline 40 & $13,18 \pm 0,34^{\mathrm{dc}}$ & $14,87 \pm 0,34^{\mathrm{abc}}$ & $14,54 \pm 1,07^{\mathrm{bc}}$ \\
50 & $14,64 \pm 0,11^{\mathrm{abc}}$ & $15,65 \pm 0,49^{\mathrm{ab}}$ & $15,12 \pm 0,88^{\mathrm{abc}}$ \\
60 & $13,37 \pm 0,78^{\mathrm{dc}}$ & $13,57 \pm 0,48^{\mathrm{bcd}}$ & $14,94 \pm 0,56^{\mathrm{abc}}$ \\
70 & $10,27 \pm 0,95^{\mathrm{e}}$ & $13,47 \pm 0,66^{\mathrm{a}}$ & $11,57 \pm 0,30^{\mathrm{e}}$ \\
\hline \multicolumn{4}{c}{$\mathbf{E ~ ( \% )}$} \\
\hline 40 & $33,96 \pm 0,80^{\text {ed }}$ & $39,44 \pm 1,49^{\mathrm{abc}}$ & $34,25 \pm 0,65^{\mathrm{ed}}$ \\
50 & $33,21 \pm 0,30^{\text {ed }}$ & $39,10 \pm 1,80^{\mathrm{ab}}$ & $39,24 \pm 0,80^{\mathrm{abc}}$ \\
70 & $34,05 \pm 1,73^{\mathrm{dc}}$ & $35,73 \pm 0,75^{\mathrm{cde}}$ & $40,00 \pm 1,12^{\mathrm{abc}}$ \\
70 & $32,11 \pm 0,24^{\mathrm{e}}$ & $39,12 \pm 0,80^{\mathrm{abc}}$ & $37,05 \pm 2,46^{\mathrm{cbd}}$ \\
\hline
\end{tabular}
obtidas por meio do "teste TUKEY".

\section{4 - Permeabilidade ao vapor de água}

Os valores de permeabilidade ao vapor de água para filmes modificados enzimaticamente (FME), nativos (FN) e termicamente tratados (FC) em função da temperatura de reação encontram-se na Tabela 2 . Nas temperaturas de $40 \mathrm{e}$ $50{ }^{\circ} \mathrm{C}$, os filmes modificados enzimaticamente apresentaram uma diminuição significativa da permeabilidade ao vapor de água em relação ao filme nativo (FN) e ao termicamente tratado $(\mathrm{FC})$. Os resultados sugerem que, nestas temperaturas, a introdução de ligações cruzadas é favorecida, e que a introdução destas provocou mudanças morfológicas da matriz polimérica permitindo uma configuração intermediária com algum grau de renaturação das triplas hélices, favorecendo as propriedades de barreira à água desses filmes, embora o aumento do grau de ligações cruzadas pareça dificultar a formação de zonas de junção características da formação da matriz polimérica para a gelatina [4]. Estudos envolvendo a aplicação da enzima transglutaminase em géis [8] e em filmes à base de concentrado protéico de soro de leite [12] observaram diminuição da permeabilidade ao vapor de água da mesma forma como observado no presente trabalho. Resultados opostos foram obtidos por YILDIRIM \& HETTIARACHCHY [26] para filmes à base de proteínas do soro de leite e globulina 11S modificados com transglutaminase, em que os autores sugeriram mudanças na morfologia do filme como decorrência da formação de numerosos poros com dimensão superior aos não modificados e, portanto, causando um aumento na permeabilidade ao vapor de água.

Observou-se, ainda, que os filmes tratados termicamente (FC) apresentaram uma redução da permeabilidade ao vapor de água em relação ao filme nativo (FN). Uma vez que o tratamento térmico não provocou uma diminuição da solubilidade e um aumento das propriedades mecânicas, esta diminuição verificada possivelmente está relacionada com mudanças morfológicas. A morfologia do filme está relacionada com as características da matriz polimérica após o resfriamento, que por sua vez está associada à concentração, ao grau de ligações cruzadas, ao tipo de solvente e à temperatura utilizados [1, 23].
TABELA 2 - Permeabilidade ao vapor de água (PVA, $25^{\circ} \mathrm{C}$ e $50 \%$ UR) em função da temperatura de produção de filmes à base de gelatina: modificado enzimaticamente ( $\mathrm{FME})$, termicamente tratado (FC) e nativo (FN).

\begin{tabular}{cccc}
\hline $\mathbf{T}\left({ }^{\circ} \mathbf{C}\right)$ & \multicolumn{3}{c}{ PVA $\left(\mathbf{g ~ m m} / \mathbf{k P a ~ h ~ ~ ^ { 2 } )}\right.$} \\
\cline { 2 - 4 } & FME & FN & FC \\
\hline 40,0 & $0,124 \pm 0,003^{\mathrm{h}}$ & $0,229 \pm 0,001^{\mathrm{a}}$ & $0,153 \pm 0,002^{\mathrm{f}}$ \\
50,0 & $0,120 \pm 0,001^{\mathrm{h}}$ & $0,198 \pm 0,003^{\mathrm{b}}$ & $0,168 \pm 0,002^{\mathrm{de}}$ \\
60,0 & $0,179 \pm 0,003^{\text {cd }}$ & $0,184 \pm 0,002^{\mathrm{c}}$ & $0,141 \pm 0,001^{\mathrm{g}}$ \\
70,0 & $0,158 \pm 0,006^{\text {ef }}$ & $0,218 \pm 0,003^{\mathrm{a}}$ & $0,165 \pm 0,004^{\mathrm{e}}$ \\
\hline
\end{tabular}

$\mathrm{a}-\mathrm{h}$ : letras diferentes representam diferença significativa $(\mathrm{p}<0,05)$ entre as médias obtidas por meio do "teste TUKEY".

\section{5 - Cor}

Pode-se verificar que a temperatura (Tabela 3), na faixa estudada, não afetou de maneira considerável os parâmetros de cor e opacidade em nenhum dos filmes estudados. Por outro lado, RHIM et al. [18], para filmes à base de isolado protéico de soja submetido a tratamento térmico $\left(\mathrm{L}^{*}=91,6\right.$; $\left.a^{*}=2,18 ; b^{*}=20,67\right)$ verificaram alterações significativas em relação ao filme controle sem tratamento $\left(\mathrm{L}^{*}=93,0\right.$; $\mathrm{a}^{*}=-2,14 ; \mathrm{b}^{*}=14,40$ ), enquanto PASCHOALICK et al. [16], para filmes à base de proteínas miofibrilares, observaram um aumento da opacidade dos filmes com o aumento da temperatura de fabricação e da concentração de plastificante utilizada (glicerol).

Verificou-se ainda que o tratamento enzimático provocou aumento significativo do parâmetro b*, especialmente às temperaturas de 40 e $50{ }^{\circ} \mathrm{C}$, indicando uma coloração mais amarela em relação aos outros tratamentos, embora diferenças visuais não tenham sido detectadas. Informações sobre variações de cor/opacidade devido ao tratamento enzimático de intercruzamento não foram encontrados na literatura para filmes comestíveis e ou biodegradáveis.

Alterações de cor relacionadas ao aumento do grau de intercruzamento da matriz polimérica filmogênica, decorrentes de tratamentos químicos, foram, entre outros, reportados para filmes à base de glúten tratado com formaldeido [14] e para filmes de gelatina tratados com glutaraldeído [20] e com formaldeido e glioxal [6].

\section{4 - CONCLUSÕES}

A temperatura de reação não afetou fortemente a solubilidade ou as propriedades mecânicas dos filmes à base de gelatina. Verificou-se, entretanto, que filmes produzidos com a reticulação enzimática na temperatura de $50{ }^{\circ} \mathrm{C}$ apresentaram permeabilidade ao vapor de água significantemente inferior aos produzidos nas demais temperaturas e tratamentos (FN e FC). Esse resultado pode estar relacionado a uma melhor estruturação da matriz polimérica após a reticulação enzimática. O tratamento térmico também provocou redução da permeabilidade ao vapor de água, sugerindo alterações no balanço de interações polímero-polímero e polímero-solvente decorrentes das diferenças no histórico térmico das soluções filmogênicas. 
TABELA 3 - Parâmetros de cor ("L*", "a*”, "b*” e opacidade) em função da temperatura de processo de filmes à base de gelatina: modificado enzimaticamente (FME), termicamente tratado (FC) e filme nativo (FN).

\begin{tabular}{cccccc}
\hline Filme & $\mathbf{T}\left({ }^{\circ} \mathbf{C}\right)$ & $\mathbf{L}^{*}$ & $\mathbf{a}^{*}$ & $\mathbf{b}^{*}$ & Opacidade (\%) \\
\hline FME & 40 & $84,08 \pm 0,17^{\mathrm{a}}$ & $-0,43 \pm 0,02^{\text {abc }}$ & $2,06 \pm 0,02^{\mathrm{ab}}$ & $16,87 \pm 0,06^{\mathrm{a}}$ \\
& 50 & $84,09 \pm 0,05^{\mathrm{a}}$ & $-0,48 \pm 0,01^{\mathrm{bc}}$ & $2,10 \pm 0,04^{\mathrm{a}}$ & $16,89 \pm 0,01^{\mathrm{a}}$ \\
& 60 & $84,20 \pm 0,08^{\mathrm{a}}$ & $-0,47 \pm 0,01^{\mathrm{bc}}$ & $1,93 \pm 0,03^{\mathrm{c}}$ & $16,81 \pm 0,05^{\mathrm{a}}$ \\
& 70 & $84,18 \pm 0,00^{\mathrm{a}}$ & $-0,49 \pm 0,03^{\mathrm{bc}}$ & $1,98 \pm 0,01^{\mathrm{bc}}$ & $16,96 \pm 0,09^{\mathrm{a}}$ \\
\hline FN & 40 & $84,20 \pm 0,02^{\mathrm{a}}$ & $-0,38 \pm 0,01^{\mathrm{a}}$ & $1,40 \pm 0,03^{\mathrm{a}}$ & $17,00 \pm 0,04^{\mathrm{a}}$ \\
& 50 & $84,05 \pm 0,04^{\mathrm{a}}$ & $-0,49 \pm 0,02^{\mathrm{dc}}$ & $1,54 \pm 0,01^{\mathrm{ef}}$ & $16,85 \pm 0,08^{\mathrm{a}}$ \\
& 60 & $84,21 \pm 0,11^{\mathrm{a}}$ & $-0,42 \pm 0,01^{\mathrm{ab}}$ & $1,64 \pm 0,02^{\mathrm{d}}$ & $16,92 \pm 0,01^{\mathrm{a}}$ \\
& 70 & $84,30 \pm 0,08^{\mathrm{a}}$ & $-0,45 \pm 0,01^{\mathrm{ab}}$ & $1,64 \pm 0,04^{\mathrm{d}}$ & $16,95 \pm 0,14^{\mathrm{a}}$ \\
\hline FC & 40 & $83,83 \pm 0,44^{\mathrm{a}}$ & $-0,55 \pm 0,02^{\mathrm{d}}$ & $1,48 \pm 0,02^{\mathrm{gf}}$ & $17,22 \pm 0,11^{\mathrm{a}}$ \\
& 50 & $84,19 \pm 0,01^{\mathrm{a}}$ & $-0,47 \pm 0,02^{\mathrm{bc}}$ & $1,59 \pm 0,02^{\mathrm{ed}}$ & $16,97 \pm 0,05^{\mathrm{a}}$ \\
& 60 & $84,24 \pm 0,08^{\mathrm{a}}$ & $-0,42 \pm 0,01^{\mathrm{ab}}$ & $1,47 \pm 0,03^{\mathrm{gf}}$ & $16,95 \pm 0,05^{\mathrm{a}}$ \\
& 70 & $84,12 \pm 0,21^{\mathrm{a}}$ & $-0,45 \pm 0,01^{\mathrm{bc}}$ & $1,64 \pm 0,01^{\mathrm{d}}$ & $16,73 \pm 0,03^{\mathrm{a}}$ \\
\hline
\end{tabular}

Nota: letras diferentes, na mesma coluna, representam diferença significativa ( $p<0,05$ ) entre as médias obtidas por meio do "teste TUKEY".

\section{5 - REFERÊNCIAS BIBLIOGRÁFICAS}

[1] ACHET, D.; HE, X. W. Determination of the renaturation level in gelatin films. Polymer, v. 36, n. 4, p. 787-791, 1995.

[2] ASTM D882-95. Standard test method for tensile properties of thin plastic sheeting. Annual Books of ASTM Standards, p. 182-188, 1995.

[3] ASTM E 96-95. Standard test method for water vapor transmission of materials. Annual Books Of ASTM Standards, p. 785-792, 1995.

[4] BABIN, H.; DICKINSON, E. Influence of transglutaminase treatment on the thermoreversible gelation of gelatin. Food Hydocolloids, v. 15, n. 3-4, p. 271-276, 2001.

[5] BALDWIN, E. A.; NISPEROS-CARRIERO, M. O.; BANKER, R. A. Use of edible coating to preserve quality of lightly and slightly process products. Critical Reviews in Food Science and Nutrition, v. 36, n. 6, p. 509-524, 1995.

[6] CARVALHO, R. A.; GROSSO, C. R. F. Properties of Chemically Modified Films. Brazilian Chemical Jounal of Chemical Engineering, v. 23, n. 1, p. 45-53, 2006.

[7] CUQ, B.; GONTARD, N.; CUQ, J. L.; GUILBERT, S. Selected functional properties of fish myofribilar protein-based films affected by hidrophilic plasticizers. Journal of Agricultural and Food Chemistry, v. 45, n. 3, p. 622-626, 1997.

[8] FÆRGEMAND, M.; QVIST, K. B. Transglutaminase: effect on rheological properties, microestructure and permeability of set style acid skim milk gel. Food Hidrocolloids, v. 11, n. 1, p. 287-292, 1997.

[9] GÓMEZ-GUILlÉN, M. C.; SARABIA, A. I.; SOLAS, M. T.; MONTERO P. Effect of microbial transglutaminase on the functional properties of megrim (Lepidorhomombus boscii) skin gelatin. Journal of the Science of Food and Agriculture, v. 81, n. 7, p. 665-673, 2001.

[10] JANGCHUD, A.; CHINNAN, M. S. Peanut protein film as affected by drying temperature and $\mathrm{pH}$ of film forming solution. Journal of Food Science, v. 64, n. 1, p. $153-157,1999$.

[11] LEDWARD, D.A. Gelation of Gelatin. In: Functional Properties of Food Macromolecules, Edr. J. R.
MITCHELL \& D. A. LEDWARD, Elsevier Applied Science Publishers, 1986, ch. 4, p. 171-201.

[12] LI, P.; CHEN, H. Transglutaminase catalyzed crosslinking on functional properties of whey protein-based edible films. In: 1999 IFT Annual Meeting, Chicago (USA). IFT Annual Meeting Abstracts, n. 79A-6, 1999.

[13] LORENZEN, P. C. Techno-functional properties of transglutaminase-treated milk proteins. Milchwissenschaft, v. 5, n. 12, p. 667-6670, 2000.

[14] MICARD, V.; BALAMRI, R.; MOREL, M.-H.; GUILBERT, S. Properties of chemically and physically treated wheat gluten films. Journal of Agricultural and Food Chemistry, v. 48, n. 7, p. 2948-2953, 2000.

[15] NIO, N.; MOTOKI, M.; TAKINAMI, K. Gelation mechanism of protein solution by transglutaminase. Agricultural and Biologycal Chemistry, v. 50, n. 4, p. 851-855, 1986.

[16] PASCHOALICK, T. M.; GARCIA, F. T.; SOBRAL, P. J. A.; HABITANTE, A. M. Q. B. Characterization of some functional properties of edible films based on muscle proteins of Nile Tilapia. Food Hydrocolloids, v. 17, n. 4, 419-427, 2003.

[17] PÉRES-GAGO, M. B.; NADAUD, P.; KROCHTA, J. M. Water vapor permeability, solubility and tensile properties of heat-denatured versus native whey protein films. Journal of Food Science, v. 64, n. 6, p. 1034-1037, 1999.

[ 18] RHIM, J. W.; GENNADIOS, A.; HANDA, A.; WELLER, C. L.; HANDA, M.A. Solubility, tensile, and color properties of modified soy protein isolated films. Journal Agricultural and food Chemistry, v. 48, n. 10, p. 4937-4841, 2000.

[19] SAKAMOTO, H.; KUMAZAMA, Y.; MOTOKI, M. Strength of protein gels prepared with microbial transglutaminase as related to reaction conditions. Journal of Food Science, v. 59, n. 4, p. 866-871, 1994.

[20] SARMENTO, A. L. S C. Elaboração e Caracterização de biofilmes a partir de gelatina reticulada. Campinas, 1999, 149 p. Dissertação (mestre em Engenharia de Alimentos) - Faculdade de Engenharia de Alimentos, Universidade estadual de Campinas (UNICAMP). 
[21] SOBRAL, P. J. A. Propriedades funcionais de biofilmes de gelatina em função da espessura. Ciência \& Engenharia, v. 8, n. 1, p. 60-7, 1999.

[22] SOBRAL P. J. A.; MENEGALLI F. C.; HUBINGUER, M. D.; ROQUES, M. A. Mechanical, water vapor barrier and thermal properties of gelatin based edible films. Food Hydrocolloids, v. 15, n. 4-6, 423-32, 2001.

[23] STAINSBY, G. The gelatin gel and the sol-gel transformation. In: The Science and Technology of Gelatin, New York, Edr. G. A. WARD \& A. COURTS, Academic Press, 1977, ch. 6, p. 179-208.

[24] STUCHELL, Y. M.; KROCHTA, J. M. Enzymatic treatments and thermal effects on edible soy protein films. Journal of Food Science, v. 59, n. 6, p. 1332-1337, 1994.

[25] YILDIRIM, M.; HETTIARACHCHY, N. S. Biopolymers produced by cross-linking soybean 11S globulin with whey proteins using transglutaminase. Journal of Food Science, v. 62, n. 2, p. 270-275, 1997.
[26] YILDIRIM, M.; HETTIARACHCHY, N. S. Properties of films produced by cross-linking whey protein and $11 \mathrm{~S}$ globulin using transglutaminase. Journal of Food Science, v. 63, n. 2, p. 248-252, 1998.

[27] ZHU, Y.; RINZEMA, A.; TRAMPER, J.; BOL, J. Microbial transglutaminase - a review of its production and application in food processing. Applied Microbiologycal Biotechnology, v. 44, n. 2, p. 277-282, 1995.

[28] ZIEGLER, G. R.; FOEGEDING, E. A. The gelation of proteins. Advances in Food and Nutrition Research, v. $34,203-298,1990$.

\section{6 - AGRADECIMENTOS}

À FAPESP pela bolsa de doutorado da autora R. A. Carvalho, à GELITA SOUTH AMERICA (São Paulo, Brasil) pela doação da gelatina utilizada e à AJINOMOTO pela doação da enzima transglutaminase. 